\title{
Inhibition on Lipoxygenase of the Flavonoids from Selaginella Labordei
}

\begin{abstract}
LOX inhibitory activities of six Flavonoids compounds from medicinal plants of Selaginella labordei are investigated. Six Flavonoids have been isolated from the active fraction, and the $50 \%$ inhibitory concentration (IC50) of the each sample against LOX in vitro was determined, using a ultraviolet spectrophotometer with kinetics analysis software. The six Flavonoids all have obvious inhibitory action on lipoxygenase. Among them, two kinds of Flavonoids were more active in inhibiting lipoxygenase than others $\square$ the IC50 of amentoflavone was $7.03 \mu \mathrm{M}$ and robustaflavone was $8.05 \mu \mathrm{M}$. Six Flavonoids are active compounds in inhibiting lipoxygenase from $S$. labordei.
\end{abstract}

Keywords: selaginella labordei, flavonoids, lipoxygenase
Volume 6 Issue 6 - 2017

\section{Xu Jiacheng, LI Li, Chen Keli}

Traditional Chinese Medicine Resource and Compound Prescription, Hubei University of Chinese Medicine, China

Correspondence: Chen Keli, Key Laboratory of Ministry of Education for Traditional Chinese Medicine Resource and Compound Prescription, Hubei University of Chinese Medicine, Wuhan 430065, PR, China, Email kelichen@I26.com

Received: December 09, 2016 | Published: May 05, 2017

\section{Introduction}

Selaginella labordei Hieron. ex Christ is a rare medicinal plant from Selaginellaceae with activities in anti-tumor, ${ }^{1}$ anti-virus ${ }^{2}$ inhibiting xanthine oxidase ${ }^{3-4}$ and lipoxygenase (LOX). ${ }^{5}$ LOXs are involved in the biosynthesis path of leukotrienes, prostaglandins and induce the oxidation of fatty acid, and also involved in the pathologic process of inflammation, mutagenesis and cancer. ${ }^{6}$ It is found that the ethyl acetate extracts from the whole herb of S. labordei showed obvious inhibitory activities against LOX according to our investigation. ${ }^{5}$ But the concrete active compounds inhibiting LOX have not been known yet. So, six kinds of Flavonoids compounds were isolated from the active fraction ethyl acetate extract of Selaginella labordei under the direction of activity test. ${ }^{3,7}$ In this paper, lipoxygenase inhibitory activities in vitro of 6 Flavonoids compounds isolated from $S$. labordei were determined, using a ultraviolet spectrophotometer with kinetics analysis software, so that to provide with experimental basis for clinical applications of this herb.

\section{Materials}

\section{Reagents and apparatus}

Lipoxygenase and linoleic acid were purchased from Sigma Chemical Co.(St.Louis,MD). Quercetin from National Institute for the Control of Pharmaceutical and Biological Products. Dimethyl sulfoxide (DMSO) and Tween-20 from Amresco Inc (USA). All other reagents used were of analytical grade. DU640 Spectrophotometer with dynamics/time software (Beckman, USA).

\section{Plant materials and compounds}

The plant materials of Selaginella labordei were collected in September, 2005 from Lushan Mountain of Jiangxi Province, China, and authenticated by Professor Chen Keli, and the plant specimens were deposited at the herbarium of the Hubei University of Traditional Chinese Medicine. The air-dried and powdered plant material was extracted at room temperature with EtOH, then extracted with EtOAc, separated and purified to afford the total Flavonoids by defatting and macroporous resin method. The total Flavonoids was further separated and refined to give six flavone compounds. The purity of each of the six Flavonoids was more than $97 \%$ quantitated by HPLC. The structures of these compounds (Figure1) were elucidated by means including UV, IR, 1H-NMR, 13C-NMR, HSQC, HMBC, HRTOFMS, EI-MS, DEPT and COSY., $3,7,8$

\section{Preparation of test solution}

Phosphate buffer (0.2 M, pH 7.0): Dissolve K2HPO4 11.34g, KH2PO4 $4.75 \mathrm{~g}$, in $500 \mathrm{~mL}$ water. Enzyme solution (11945units $/ \mathrm{mL}$ ): Dissolve $2.7 \mathrm{mg}$ lipoxygenase (110,600units $/ \mathrm{mg}$ ) in $1 \mathrm{~mL}$ phosphate buffer as stock solution, Get $40 \mathrm{~mL}$ stock solution into $960 \mu \mathrm{L}$ phosphate buffer for assay. In the process of testing the solution must be keep at low-temperature with ice pack. Substrate solution: $0.01 \mathrm{M}$ substrate stock solution: $157.2 \mathrm{~mL}$ linoleic acid, $157.2 \mathrm{~mL}$ Tween-20 and $10 \mathrm{~mL}$ deionised water, was clarified by adding $1 \mathrm{~mL}$ of $1 \mathrm{M} \mathrm{NaOH}$ and made to $50 \mathrm{~mL}$ with water (Made fresh daily) $\square$ Substrate buffer solution: substrate stock solution was diluted with $0.2 \mathrm{M}$ phosphate buffer to give $3.3 \mathrm{mM}$ substrate, flush with oxygen for $2 \mathrm{~min}$.

\section{Sample solution and reference substance solution}

Weigh accurately all the above samples and positive reference substance quercetin and then dissolve respectively in DMSO (final concentrations $<1 \%$ ), and diluted appropriately in the experiment to afford various concentration of solutions.

\section{Methods}

\section{Determination of LOX activity}

Experiment was made, as described in related literature, ${ }^{9}$ the concentration of lipoxygenase being $11945 \mathrm{units} / \mathrm{mL}$, and increase value in absorbance at $234 \mathrm{~nm}$ was recorded at $5 \mathrm{~s}$ intervals for $5 \mathrm{~min}$. In any appropriate long period of time, absorbance was increased linearly with time, and the slope was reaction rate $(\mathrm{dA} / \mathrm{min})$. The greater slope shows the stronger of enzyme activity.

\section{Sample determination}

The 6 Flavonoids samples were dissolved in DMSO to obtain various concentrations of solutions. To get appropriate quantity of solution into $2 \mathrm{~mL}$ quartz cuvettes, the above procedure was repeated and increase value in absorbance at $234 \mathrm{~nm}$ was recorded at $5 \mathrm{~s}$ intervals for $2 \mathrm{~min}$. Each sample was determinated 3times in parallel, and reaction rate was recorded respectively, and inhibition rate of samples was calculated with averages.

\section{Blank control}

Blank sample contains same amount DMSO in quartz cuvettes without lipoxygenase, and the above procedure was repeated, recording the changing value of absorbance. 


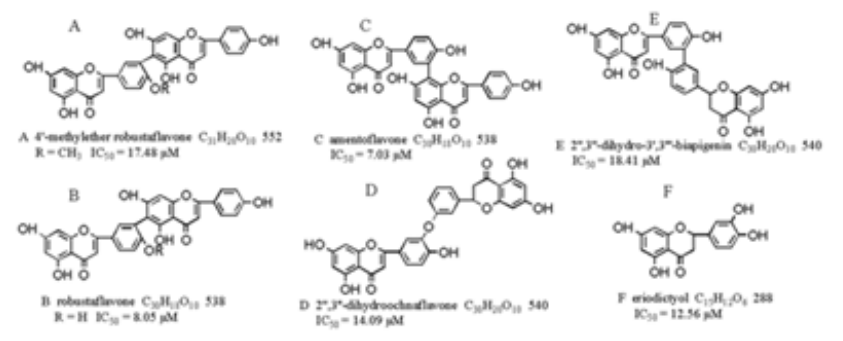

Figure I The structures of six flavone compounds.

\section{Results}

Data processing was carried on with the use of SPSS 13.0 statistical package. Firstly, inhibitory rate (IR) of samples on LOX was calculated according to the following formula: $I R=1$ - (Rs-Ro)/ (Rp-Ro) $\times 100 \%$, IR signifies inhibitory rate, Rs, Ro, Rp expressing respectively reaction rate of sample, blank and LOX in the formula. Then, regression equation was computed, taking inhibitory rate (IR) as a dependent variable and sample concentration (C) as the independent variable. Because IR and C exist the linear relationship, the $50 \%$ inhibitory concentration (IC50) of the sample was computed directly according to regression equation. The experimental results are shown in Table 1.

Table I Inhibition on LOX by six flavone compounds

\begin{tabular}{|c|c|c|c|c|}
\hline Sample & Sample name & Regression equation & $\begin{array}{l}\mathrm{IC}_{50}(\mu \mathrm{g} / \\
\mathrm{mL})\end{array}$ & $\begin{array}{l}I C_{50} \\
(\mu M)\end{array}$ \\
\hline A & $\begin{array}{l}\text { 4'-methylether } \\
\text { obustaflavone }\end{array}$ & $I_{R}=-6.937+5.902 C$ & 9.65 & 17.48 \\
\hline B & obustaflavone & $I_{R}=-1.638+11.925 C$ & 4.33 & 8.05 \\
\hline C & amentoflavone & $I_{R}=-1.934+13.739 C$ & 3.78 & 7.03 \\
\hline D & $\begin{array}{l}\text { 2",3"- } \\
\text { dihydroochnaflavone }\end{array}$ & $I_{R}=-12.785+8.253 C$ & 7.61 & 14.09 \\
\hline$E$ & $\begin{array}{l}\text { 2",3"'-dihydro-3',3"'- } \\
\text { biapigenin }\end{array}$ & $I_{R}=-2.036+5.235 C$ & 9.94 & $18.4 \mid$ \\
\hline$F$ & eriodictyol & $I_{R}=5.012+12.729 C$ & 3.53 & 12.56 \\
\hline $\mathrm{x}$ & quercetin & $I_{R}=-\mid I .8 I I+519.095 C$ & 0.12 & 0.40 \\
\hline
\end{tabular}

Note: Correlation coefficient $r>0.98$, of all samples

\section{Conclusions}

From Table 1, it is shown that six Flavonoids have obvious inhibitory action on lipoxygenase. Among them, two kinds of Flavonoids were more active in inhibiting lipoxygenase than others, the IC50 of amentoflavone was $7.03 \mu \mathrm{M}$ and robustaflavone was $8.05 \mu \mathrm{M}$. So the six Flavonoids are the active compounds inhibiting lipoxygenase from Selaginella labordei. The inhibiting action on LOX of Flavonoids from Selaginella labordei is one of the mechanisms of anti-tumor and anti-virus action of the herb.

It is shown From Figure 1 that (B) robustaflavone and (A) 4'-methylether robustaflavone belong to homologue, the difference in their structures only displays in (B) 4'-OH and (A) 4'-OMe. It is indicated from the experimental data that the activity inhibiting LOX is probably reduced to one half after the $\mathrm{H}$ in (B) 4'-OH is replaced by $\mathrm{Me}(-\mathrm{CH} 3)$, and their IC50 respectively are $8.05 \mu \mathrm{M}$ and $17.48 \mu \mathrm{M}$. This is only a preliminary inference to the relations between structure and effect, when further experimental study in more Flavonoids is obtained, also combined with computer auxiliary medicine design, and finally construction effect relations of LOX inhibitors will be confirmed and clarified.

\section{Acknowledgments}

None.

\section{Conflicts of interest}

Author declares there are no conflicts of interest.

\section{Funding}

None.

\section{References}

1. Li Juan Li, Chen Ke-Li, XU Jia-Cheng. Anti-tumor activities in vitro of extracts from Selaginella labordei", Guihaia. 2008;28(5):690-693.

2. Lei X, Chen KL, Li L, et al.Study on the inhibitory effect on Coxsackie virus B3 replication in vitro by the extracts from 7 medicinal plants of the Selaginella genus. Pharmacology and Clinics of Chinese Materia Medica. 2007;23(5):111-113.

3. Tan WJ, Xu JC, Li L, Bioactive compounds of inhibiting xanthine oxidase from Selaginellalabordei. Natural Product Research. 2009;23(4):393-398.

4. $\mathrm{Li} \mathrm{Li}, \mathrm{Keli}$ Chen, Jia-Cheng $\mathrm{Xu}$, Inhibition action on Xantine Oxidase by biflavonoids from Selaginellalabordei. The 3rd Beijing, China: International Conference on Bioinformatics and Biomedical Engineering (iCBBE)2009.

5. LI L, Chen KL, Zhu TM, et al. Inhibition of Lipoxygenase by the Extracts from the medicinal plants of Selaginella Genus. Chinese Journal of Hospital Pharmacy. 2006;26(12):1514-1517.

6. Chen K, Plumb GW, Bennett RN, Antioxidant activities of extracts from five anti-viral medicinal plants. J Ethnopharmacol. 2005;96(12):201-205.

7. XU Jiacheng, Chen KL. Study on the chemical components from Selaginellalabordei. China: Master's degree thesis, Hubei College of Traditional Chinese Medicine; 2007.

8. XU JC, Liu XQ, Chen KL. A new biflavonoid from Selaginella labordei Hieron. ex Christ. Chinese Chemical Letters. 2009;20:939-941.

9. Chen AO, Whitaker JR. Purification and characterization of a lipoxygenase from immature English peas. J Agri Food Chem. 1986;34(2):203-211. 